\title{
Multisite drainage of recalcitrant subcutaneous emphysema in thoracoscopic lung volume-reduction surgery
}

\author{
Eugenio Pompeo, MD, $\mathrm{PhD}$, Rome, Italy
}

Subcutaneous emphysema can develop after lung volumereduction surgery in the presence of major, nonsealable air leaks. ${ }^{1}$ Although this condition is nonlethal, it can cause cosmetic deformity, ${ }^{2}$ anxiety, change in voice, vision problems, dysphagia, tension phenomena, and even respiratory failure. ${ }^{3}$ In the most severe instances (recalcitrant subcutaneous emphysema), standard management, including the application of as much as $40 \mathrm{~cm} \mathrm{H}_{2} \mathrm{O}$ suction to the chest tube often proves unsatisfactory and additional drainage methods or reoperation have been anecdotally advocated to achieve decompression. ${ }^{2-4}$

I report here a novel multisite subcutaneous drainage method that has been successfully used at my institution to treat recalcitrant subcutaneous emphysema occurring after thoracoscopic lung volume-reduction surgery.

\section{CLINICAL SUMMARY}

With the patient placed in the lateral decubitus position, a curvilinear, $5-\mathrm{cm}$ wide subcutaneous tunnel is created bluntly to ensure free communication among all thoracoscopic port sites. Thereafter, a large, multifenestrated silicone drainage tube is inserted anteriorly and progressively pulled subcutaneously to lie eventually just below the ports' skin incisions. The tube is then connected to a Heimlich valve without suction, and the skin incisions are sutured (Figure 1).

Removal of the subcutaneous drainage is performed before discharge, as soon as temporary occlusion of the tube for 2 hours is not associated with recurrence of the emphysema.

I have used this method in the treatment of 6 patients $(2.9 \%)$ with recalcitrant subcutaneous emphysema, out of a total of 206 patients undergoing thoracoscopic lung volume-reduction through December 2010. For study purposes, a subcutaneous emphysema was considered recalcitrant if it caused progressively deteriorating cosmetic deformity despite optimized standard management, including the presence of intrapleural, patent, and functional chest tubes put on high suction.

\footnotetext{
From the Department of Thoracic Surgery, Policlinico Tor Vergata, Tor Vergata University, Rome, Italy.

Disclosures: Author has nothing to disclose with regard to commercial support.

Received for publication Feb 5, 2013; revisions received May 2, 2013; accepted for publication May 9, 2013; available ahead of print July 8, 2013.

Address for reprints: Eugenio Pompeo, MD, PhD, Section of Medical and Surgical Lung Diseases, Department of Biomedicine and Prevention, Tor Vergata University, Via Montpellier, 1, 00133 Rome, Italy (E-mail: pompeo@med.uniroma2.it). J Thorac Cardiovasc Surg 2013;146:722-4

$0022-5223 / \$ 36.00$

Copyright (c) 2013 by The American Association for Thoracic Surgery

http://dx.doi.org/10.1016/j.jtcvs.2013.05.009
}

The subcutaneous drainage was placed postoperatively in 4 patients in whom subcutaneous emphysema extended to multiple anatomic compartments. In another 2 patients with nonsealable air leaks despite intraoperative attempts at restapling, the subcutaneous drainage was inserted immediately after the procedure, when the subcutaneous emphysema was still limited to the chest.

There were no procedure-related complications, and in all instances the subcutaneous emphysema resolved within 48 hours after drainage. At discharge, the subcutaneous tube was always removed, and no patients had recurrence of the subcutaneous emphysema (Table 1).

\section{DISCUSSION}

The development of subcutaneous emphysema entails migration of air from the bronchial tree to the subcutaneous space through one or more defects in the chest wall. This migration is facilitated, in the presence of air leaks, by intermittent, highly positive intrapleural pressure, coughing, lung hyperinflation, inadvertent kinking or angulation of the chest tubes, or a combination of these causes.

In observations at my institution, recalcitrant subcutaneous emphysema after thoracoscopic lung volume-reduction surgery, for which a 4-trocar access is routinely used, may initially develop around the superior trocars' incisions, particularly the anterior-superior one. It then rapidly extends to other compartments, including the neck, head, and even groin.

Cerfolio and coworkers ${ }^{2}$ reported on a series of 255 patients with symptomatic subcutaneous emphysema. Maximized chest tube suction alone was not sufficient to control the condition in 85 patients; in 64 of these, thoracoscopy with pneumolysis and chest tube replacement successfully resolved the emphysema.

Other reported methods to drain recalcitrant subcutaneous emphysema include insertion of additional chest drainage, infraclavicular skin incisions, and subcutaneous insertion of intravenous catheters or silicone drains connected to colostomy bags. ${ }^{2-4}$ These reports have discussed pros and cons of the various treatments, but all referred to subcutaneous emphysema developing after open surgery. Thoracoscopic lung volume-reduction surgery raises additional concerns related to the presence of multiple chest wall defects that can independently supply the subcutaneous emphysema. The rationale of the method described here is thus to create a preferential subcutaneous pathway that puts into wide communication all chest wall defects, which may feed the air collection. I prefer to avoid suction, because in 1 case 

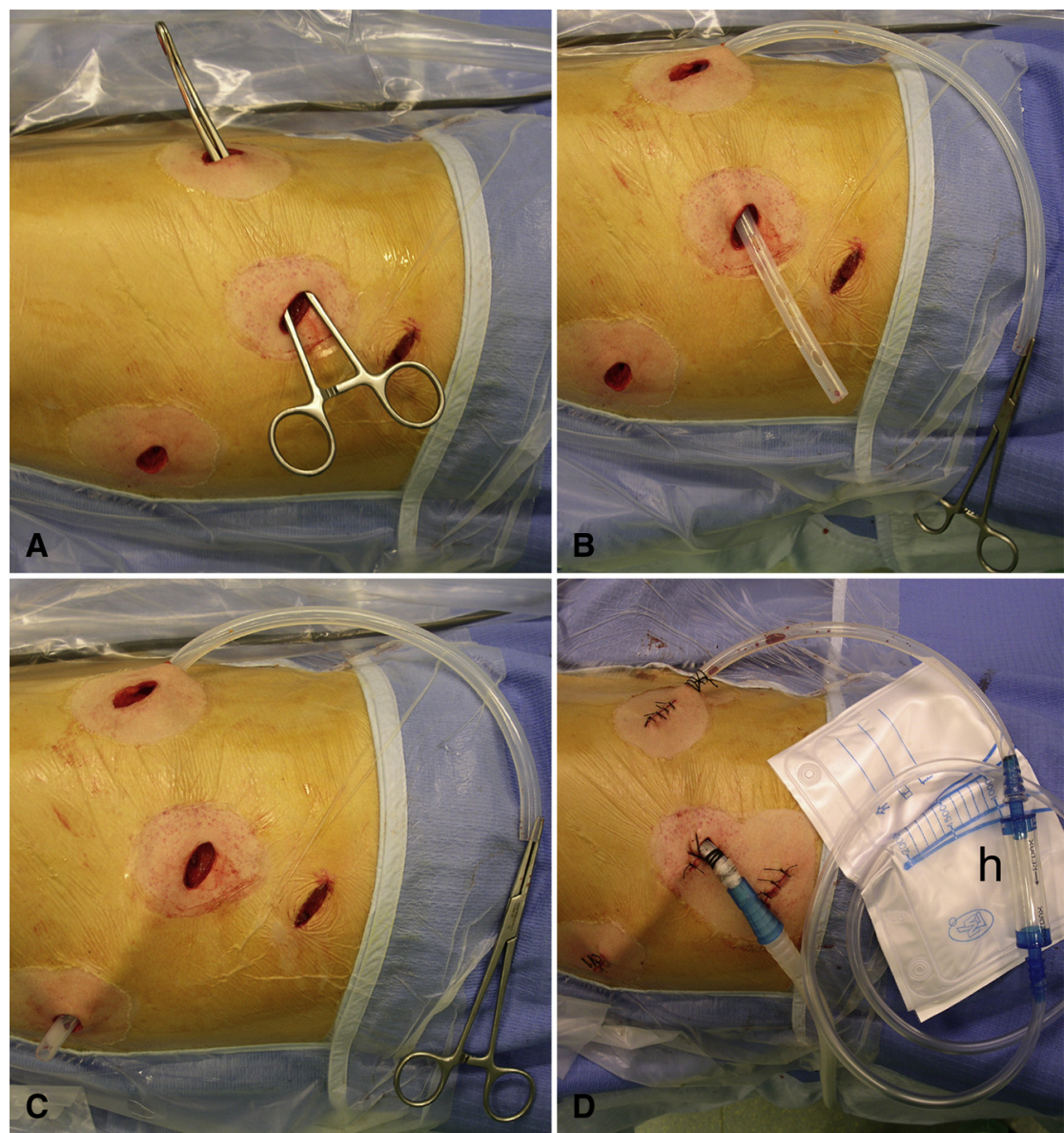

FIGURE 1. Operative steps of the subcutaneous drainage method. A, Subcutaneous communication between port sites is created bluntly with the aid of ring forceps. B, A large silicone tube is inserted anteriorly and progressively pulled posteriorly. C, Eventually, this tube drains the 3 port incisions, including the chest tube entry site. D, In the final configuration, the tube is connected to a Heimlich valve $(h)$.

this resulted in a temporary obstruction of the subcutaneous tube, possibly as a result of wedging of fat into the tube fenestrations. Theoretic advantages of this method include achievement of simultaneous drainage of multiple sites by a single, large, and totally extrapleural tube; avoidance of reoperative surgery and supplemental chest tube insertion, which carry more morbidity and are painful; and facilitated nurse care, with minimal risk of kinking because of the posterior-to-anterior direction of the subcutaneous tube.
The goal of this simple method is not to treat the causative mechanism, but rather to resolve rapidly some of the distressing clinical and cosmetic consequences of recalcitrant subcutaneous emphysema that can negatively affect both perioperative quality of life and hospital stay duration.

In conclusion, I have described here a novel, subcutaneous drainage method that reliably, safely, and rapidly resolves recalcitrant subcutaneous emphysema occurring after thoracoscopic lung volume-reduction surgery. Further

TABLE 1. Patient data and results

\begin{tabular}{lcccccc}
\hline Case & $\begin{array}{c}\text { Chest } \\
\text { tubes (n) }\end{array}$ & SE extension & $\begin{array}{c}\text { Timing of } \\
\text { subcutaneous drainage }\end{array}$ & $\begin{array}{c}\text { SE postdrainage } \\
\text { resolution time (h) }\end{array}$ & $\begin{array}{c}\text { Hospital } \\
\text { stay (d) }\end{array}$ & SE postdischarge outcome \\
\hline 1 & 2 & C, N, F & POD 2 & 48 & 10 & No relapse; minor air leak for 6 d* \\
2 & 1 & C & End operation & 12 & 12 & No relapse \\
3 & 2 & C, N, F & POD 3 & 48 & 10 & No relapse; minor air leak for 10 d* \\
4 & 1 & C, N, F & POD 2 & 24 & 11 & No relapse; minor air leak for 6 d* \\
5 & 2 & C, N, F, G & POD 3 & 48 & 15 & No relapse \\
6 & 2 & C & End operation & 12 & 13 & No relapse \\
\hline
\end{tabular}

Resolution of subcutaneous emphysema was determined as disappearance of any cosmetic deformity. Lack of relapse at 3-month follow-up was considered to indicate no relapse. $S E$, Subcutaneous emphysema; $C$, chest; $N$, neck; $F$, face; $P O D$, postoperative day; $G$, groin. *In 3 cases, a single chest tube was maintained at discharge and connected to a Heimlich valve. 
investigation is warranted to confirm these preliminary findings.

\section{References}

1. Tacconi F, Pompeo E, Mineo TC. Duration of air leak is reduced after awake nonresectional lung volume reduction surgery. Eur J Cardiothorac Surg. 2009;35: 822-8; discussion 828
2. Cerfolio RJ, Bryant AS, Maniscalco LM. Management of subcutaneous emphysema after pulmonary resection. Ann Thorac Surg. 2008;85:1759-63; discussion 1764-5.

3. Matsushita T, Huynh AT, Singh T, Thomson D. Management of life-threatening subcutaneous emphysema using subcutaneous Penrose drains and colostomy bags. Heart Lung Circ. 2007;16:469-71.

4. Beck Pl, Heitman SJ, Mody CH. Simple construction of a subcutaneous catheter for treatment of severe subcutaneous emphysema. Chest. 2002;121:647-9.

\title{
Innovative techniques for thoracoscopic lobectomy in postpneumonectomy patients
}

\author{
Ryoichi Nakanishi, MD, PhD, ${ }^{\mathrm{a}}$ Shinji Shinohara, MD, ${ }^{\mathrm{a}}$ Kenji Muranaka, MD, ${ }^{\mathrm{b}}$ and Koichi Shinohara, MD, \\ Kitakyushu, Japan
}

\section{PTCS VIDEO}

Video clip is available online.

It is extremely difficult to perform a thoracoscopic lobectomy for non-small cell lung cancer in postpneumonectomy patients because lung collapse as classically practiced is not an option. Collapse of the lobe to be resected and effective retraction of the other inflated lobes allow surgeons to perform thoracoscopic procedures in such patients. This report presents several innovations regarding thoracoscopic middle lobectomy in patients with a favorable pulmonary function who previously underwent left pneumonectomy.

\section{SURGICAL PROCEDURES}

The patient was placed in a supine position under general anesthesia with a spiral endotracheal tube. A Coopdech endobronchial blocker tube (Daiken Medical, Osaka, Japan) was introduced into the lobar bronchus to be resected under bronchoscopy, performed via an endotracheal tube. The lobe to be resected collapsed after the balloon was inflated.

From the Department of Thoracic Surgery, ${ }^{\mathrm{a}}$ and the Department of Anesthesiology, ${ }^{\mathrm{b}}$ Shin-Kokura Hospital, Federation of National Public Service, Personnel Mutual Aid Associations, Kokurakita-ku, Kitakyushu, Japan.

Disclosures: Authors have nothing to disclose with regard to commercial support.

Received for publication Feb 21, 2013; revisions received April 1, 2013; accepted for publication April 9, 2013; available ahead of print June 13, 2013.

Address for reprints: Ryoichi Nakanishi, MD, PhD, Department of Thoracic Surgery, Shin-Kokura Hospital, Federation of National Public Service, Personnel Mutual Aid Associations, Kanada 1-3-1, Kokurakita-ku, Kitakyushu, 803-8505, Japan (E-mail: ryoichi@med.uoeh-u.ac.jp).

J Thorac Cardiovasc Surg 2013;146:724-5

$0022-5223 / \$ 36.00$

Copyright (c) 2013 by The American Association for Thoracic Surgery

http://dx.doi.org/10.1016/j.jtcvs.2013.04.013
The surgery was begun after confirmation of absence of hypoxemia. ${ }^{1}$

While paying close attention to avoid any injury to the inflated lung, an access window measuring $30 \mathrm{~mm}$ in length was first placed in the fourth intercostal space on the anterior axillary line because of easy access to the hilar structures and effective retraction of the lower lobe. An additional 12-mm-diameter port was placed in the fifth intercostal space on the midclavicular line for a $10-\mathrm{mm}$ thoracoscope. The inflated lower lobe then was retracted posteriorly using 2 devices (Endoractor, Kawamoto Co,

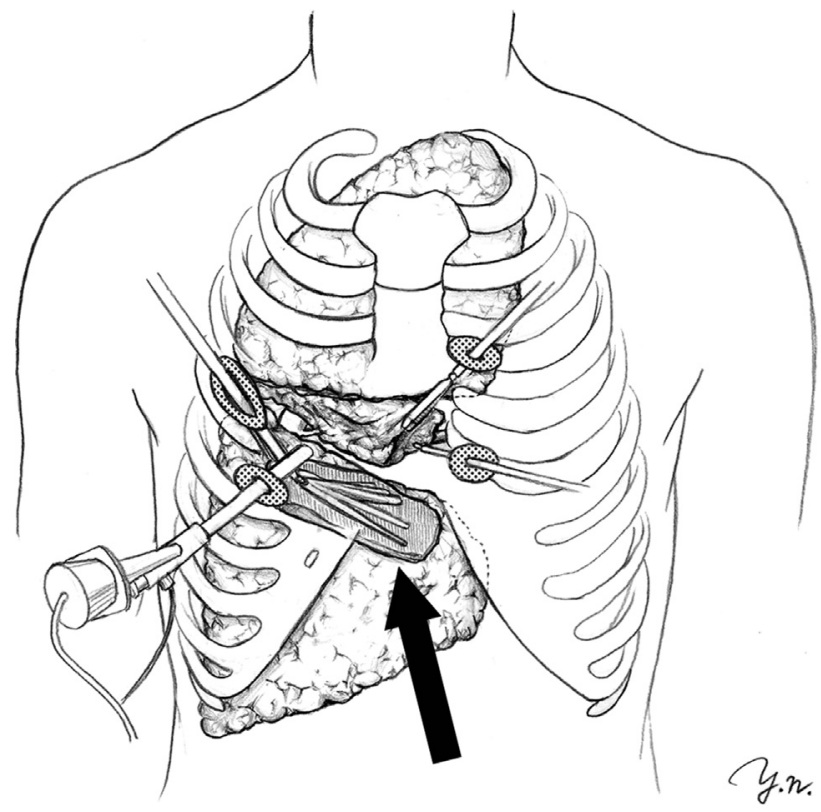

FIGURE 1. Surgical maneuvers are shown with the patient positioned in the supine position. The arrow indicates the right lower lobe, which is retracted by the Endo Retract II on contact with the swollen Endoractor sponge. 